\title{
Bottom-up effects of climate on fish populations: data from the Continuous Plankton Recorder
}

\author{
Sophie G. Pitois ${ }^{1, *}$, Christopher P. Lynam ${ }^{1}$, Teunis Jansen ${ }^{2}$, Nick Halliday ${ }^{3}$, \\ Martin Edwards ${ }^{4}$ \\ ${ }^{1}$ Cefas, Centre of Environment, Fisheries and Aquaculture Science, Pakefield Road, Lowestoft NR33 0HT, UK \\ ${ }^{2}$ DTU AQUA, National Institute of Aquatic Resources, Technical University of Denmark, Charlottenlund Castle, \\ 2920 Charlottenlund, Denmark \\ ${ }^{3}$ Marine Biological Association, The Laboratory, Citadel Hill, Plymouth PL1 2PB, UK \\ ${ }^{4}$ SAHFOS, Sir Alister Hardy Foundation for Ocean Science, The Laboratory, Citadel Hill, Plymouth PL1 2PB, UK
}

\begin{abstract}
The Continuous Plankton Recorder (CPR) dataset on fish larvae has an extensive spatio-temporal coverage that allows the responses of fish populations to past changes in climate variability, including abrupt changes such as regime shifts, to be investigated. The newly available dataset offers a unique opportunity to investigate long-term changes over decadal scales in the abundance and distribution of fish larvae in relation to physical and biological factors. A principal component analysis (PCA) using 7 biotic and abiotic parameters is applied to investigate the impact of environmental changes in the North Sea on 5 selected taxa of fish larvae during the period 1960 to 2004 . The analysis revealed 4 periods of time $(1960-1976 ; 1977-1982 ; 1983-1996$; 1997-2004) reflecting 3 different ecosystem states. The larvae of clupeids, sandeels, dab and gadoids seemed to be affected mainly by changes in the plankton ecosystem, while the larvae of migratory species such as Atlantic mackerel responded more to hydrographic changes. Climate variability seems more likely to influence fish populations through bottom-up control via a cascading effect from changes in the North Atlantic Oscillation (NAO) impacting on the hydrodynamic features of the North Sea, in turn impacting on the plankton available as prey for fish larvae. The responses and adaptability of fish larvae to changing environmental conditions, particularly to changes in prey availability, are complex and species-specific. This complexity is enhanced with fishing effects interacting with climate effects and this study supports furthering our understanding of such interactions before attempting to predict how fish populations respond to climate variability.
\end{abstract}

KEY WORDS: Fish larvae · First feeding · North Sea ecosystem · Continuous Plankton Recorder · CPR $\cdot$ Climate change

Resale or republication not permitted without written consent of the publisher

\section{INTRODUCTION}

Impacts of climate change on marine ecosystems have become increasingly evident (Brierley \& Kingsford 2009) from polar to tropical environments (Walther et al. 2002). Biological responses reported, in many cases from studies using Continuous Plankton Recorder (CPR) survey data, include: changes in phenology leading to mismatch between successive trophic levels (Edwards \& Richardson 2004); changes in the spatial distribution of primary and secondary pelagic production placing additional stress on already depleted fish populations (Richardson \& Schoeman 2004); regime shifts and changes in community structures of plankton species (Beaugrand 2004); latitudinal shifts in marine fish with potential impacts on fisheries and species richness (Perry et al. 2005, ter Hofstede et al. 2010); local 
species extinctions and invasion of non-native species (Cheung et al. 2009); and changes in spawning and migration patterns of some fish species with consequences for fisheries management (Jansen \& Gislason 2011). Climate change clearly affects many marine organisms and ecosystem functions. Therefore, in order to promote biodiversity and sustainable fisheries, it is important to further our knowledge and understanding of how climate variability influences the early life history of fish via impacts on marine food webs and the interactions between species and their changing environment.

An important indicator of climate variability which has been linked to ecosystem changes in the North Sea is the North Atlantic Oscillation (NAO). It reflects the position and strength of weather systems as they cross the North Atlantic through changes in wind speed and direction, air temperature, moisture transport and precipitation (Hurrell et al. 2003). These in turn influence the ocean and regional seas, leading to changes in water temperature and salinity, circulation patterns and vertical mixing (Visbeck et al. 2003). Variations in the NAO are hence reflected in many components of marine ecosystems, from phytoplankton, via zooplankton, to fish, and they have a wide range of indirect effects including the largescale distribution and population of fish and the production of zooplankton (Drinkwater et al. 2003, Brander \& Mohn 2004, Stige et al. 2006). Moreover, occasional extreme climatic events may enhance the effects of the NAO so much as to lead to notable biological shifts. For example, 2 exceptional oceanclimate events dubbed 'Great Salinity Anomalies' (GSA, Dickson et al. 1988, Belkin et al. 1998) led to great changes in the North Sea. The first GSA was in the late 1970s and was characterised by Atlantic inflow of cold, low-salinity water entering the North Sea from the north. The second GSA was in the late 1980s and, in contrast to the first event, was associated with warm, high-salinity water entering the North Sea from both the north and the south. Studies using CPR plankton data showed that both events had dramatic repercussions on the ecology of the North Sea, with changes in phyto- and zooplankton biomass and species composition (Reid et al. 2001a, Edwards et al. 2002), but also affecting higher trophic levels, including fish (Reid \& Edwards 2001).

The abundances of fish stocks are highly variable over time (Houde 2008), and recruitment processes are particularly difficult to monitor. The health of a fish stock depends on the number of larvae recruited to the adult population each year, and the survival of larvae is key to recruitment success and variability
(Horwood et al. 2000, Brander et al. 2001, Platt et al. 2003). As part of the plankton, fish larvae are sensitive to physical and biological changes in their environment (Taylor et al. 2002, Voigt et al. 2003, Hays et al. 2005). Direct physiological effects include metabolic and reproductive processes; fish appear to seek specific environmental conditions including temperature and salinities (Rose 2005, van der Kooij et al. 2008, Munk et al. 2009). Temperature, as one of the most important physical parameters influencing marine ecosystems, will affect the hydrographic and dynamic properties of the water column, the physiological processes (Pörtner \& Farrell 2008, Hufnagl \& Peck 2011) and the timing of spawning (Wieland et al. 2000, Genner et al. 2010, Jansen \& Gislason 2011). Further, indirect effects of temperature through the plankton are also a key determinant of recruitment in the North Sea, as shown by studies using CPR data (Beaugrand et al. 2003a, Kirby \& Beaugrand 2009, Beaugrand \& Kirby 2010). Hence, there are several physical and biological processes through which climate variability can impact recruitment (Ottersen et al. 2004a). Statistically significant correlations between fish recruitment and environmental variables have been found, but in the North Sea these often break down when tested against new data (Myers 1998). For example, Cushing (1984) obtained significant correlation between number of cod recruits and Calanus timing and abundance from the CPR survey, but the relationship did not hold at a later analysis (Brander 1992). When it comes to the link between larval growth and survival and the abundance of their prey, the relationship has remained elusive (Robert et al. 2008).

The CPR survey, which started in the North Sea in 1931 , is one of only a few long-term biological monitoring programmes worldwide, and the only one that gives systematic spatial coverage of the North Sea (Beare et al. 2003, Reid et al. 2003). The utility of this dataset has been established with the many, and increasingly complex, studies published, aiming to relate spatio-temporal changes in plankton distribution to ecosystem changes. It has also provided valuable information concerning the scale and nature of the processes affecting fish stocks (Brander et al. 2003). For example, Reid et al. (2000) found remarkable correlations suggesting strong interactions between herring stock and major prey items as plankton from the CPR. As well as zooplankton and phytoplankton, fish larvae were analysed until the 1970s (Coombs 1975, Lindley et al. 2007), but then economic constraints caused the analysis of fish larvae in CPR samples to be stopped. Recently, however, 
retrospective analysis of the CPR samples for fish larvae has been completed, and the newly available dataset offers a unique opportunity to investigate long-term changes over decadal scales in the abundance and distribution of fish larvae in relation to physical and biological factors (Edwards et al. 2011).

The morphology, size at first-feeding and behaviour of fish larvae vary across species, and it seems reasonable to assume that survival strategies are species-specific and adapted to different environmental conditions (Hillgruber et al. 1997, Erftemeijer et al. 2009). Here, we investigate the combined effect of several selected biotic and abiotic environmental variables in the North Sea over the period 1960 to 2004 . We try first to identify regimes with certain environmental conditions that are more or less favourable to the selected fish larvae, and second, to identify potential linkages between the environment and fish larvae.

\section{MATERIALS AND METHODS}

The area of study was limited to the North Sea, within latitudes 51.76 to $63^{\circ} \mathrm{N}$ and longitudes $3^{\circ} \mathrm{W}$ to $11^{\circ} \mathrm{E}$, over the period 1960 to 2004 (Fig. 1). This ensured consistency across all datasets used.

\section{The CPR survey}

The CPR is towed by ships of opportunity at speeds of 15 to 20 knots, at an approximate depth of $10 \mathrm{~m}$. Water enters the recorder through an aperture of $1.27 \mathrm{~cm}^{2}$, and is filtered through a continuously moving band of silk with an average mesh size of $270 \mu \mathrm{m}$. Each sample represents $\sim 3 \mathrm{~m}^{3}$ of filtered seawater. Methods of counting and data processing have been described by Colebrook (1975) and Batten et al. (2003). All plankton data were extracted from the CPR dataset.

\section{Ichthyoplankton}

A total of 42220 data-points in the area and timeframe selected were extracted from the CPR dataset (Fig. 1). In all, 68 taxonomic groups of ichthyoplankton were identified, but we focused on the 5 most abundant groups of fish larvae, clupeids (Clupeidae), sandeels (Ammodytidae), Atlantic mackerel Scomber scombrus, dab Limanda limanda and gadoids (Gadidae) (Fig. 2). Gadoids consisted of the following species collated in decreasing order of abundance: Merlangius merlangus, unidentified gadoids, Trisopterus esmarkii, Gadus morhua, Pollachius virens, Melanogrammus aeglefinus, T. minutus, Micromesistius poutassou, P. pollachius, Raniceps raninus and T. luscus.

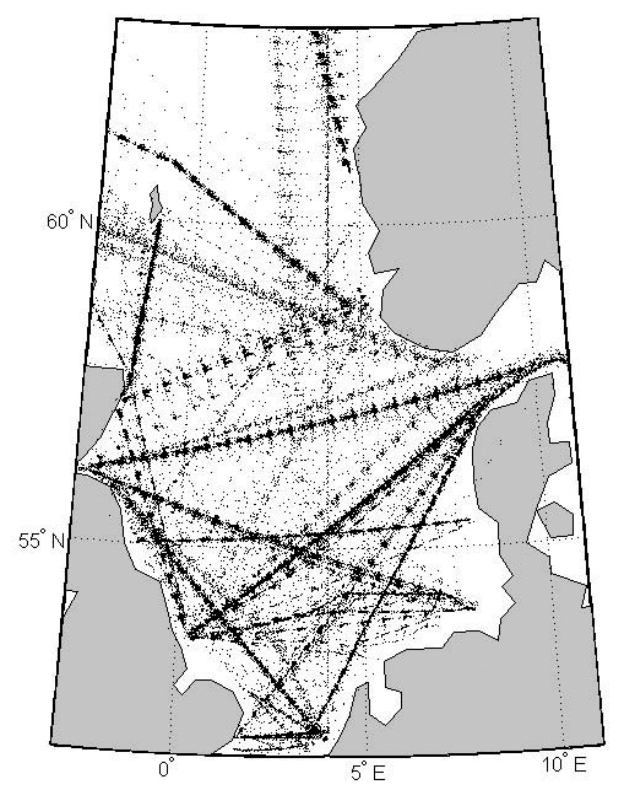

Fig. 1. Area of study $\left(51.76\right.$ to $63^{\circ} \mathrm{N}, 03^{\circ} \mathrm{W}$ to $11^{\circ} \mathrm{E}$ ) and ichthyoplankton sampling locations ( $\cdot$ ) from the Continuous Plankton Recorder over the period 1960 to 2004 (42 220 data-points)

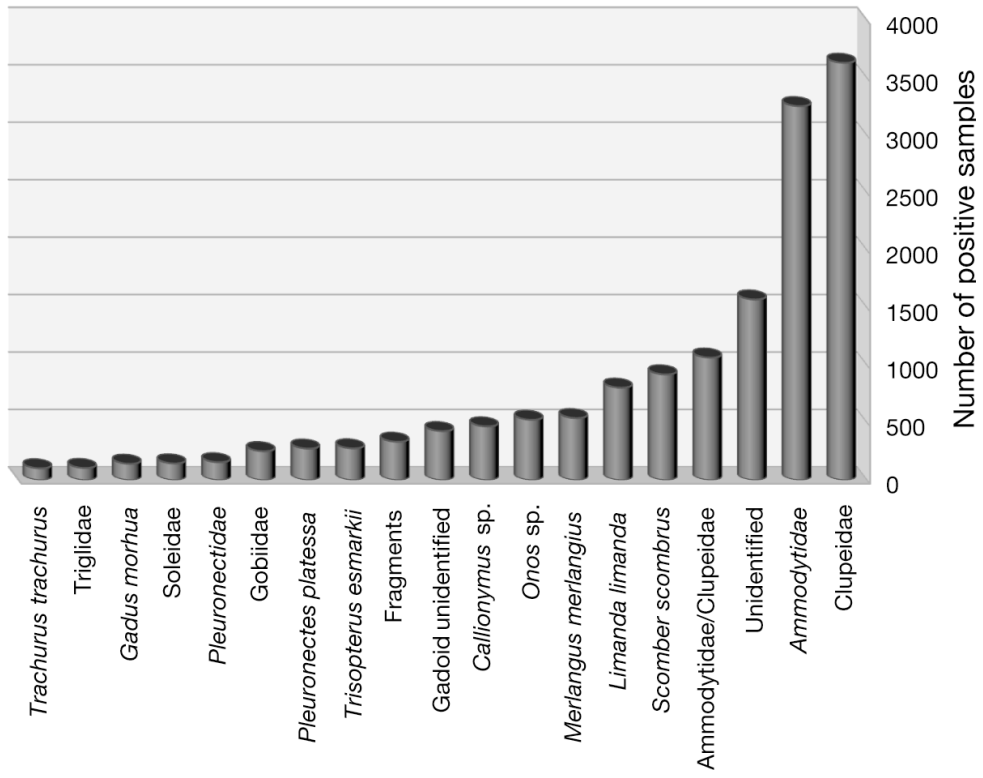

Fig. 2. Ichthyoplankton taxa identified in the North Sea area and the number of Continuous Plankton Recorder samples in which they were caught out of a total of 42220 samples. Only those groups which appeared in at least 100 samples are included in the bar chart 


\section{Zooplankton}

As a proxy for zooplankton, we extracted the abundance data for copepods and cladocerans. These 2 groups were selected because they are important prey of many fish larvae in their early stages of life. The CPR underestimates zooplankton abundance compared with other datasets (Clark et al. 2001, John et al. 2001). As we thought it important to take into account the relative contribution of each potential prey species to the total zooplankton abundance, undersampling was corrected using species-specific WP-2/CPR ratios (Pitois \& Fox 2006). We gathered together all these species-specific corrected abundances to create an index of zooplankton abundance.

\section{Phytoplankton}

The plankton chlorophyll index (CHLO) was also extracted. This index of greenness provides an indication of the quantity of primary production and hence phytoplankton, and has also been referred to as the Plankton Colour Index. We further extracted information on the abundance of the larger groups of phytoplankton, namely diatoms and dinoflagellates; abundances of individual species were collated within each of these 2 groups to create separate indices of abundance.

\section{Potential biases and limitations}

The CPR instrument, with its very small aperture and fixed sampling depth, is bound to substantially under-sample fish larvae more than it does zooplankton, but this has not yet been quantified. To obtain robust time-series to ensure that further data analysis on abundance could be performed, including seasonal and/or yearly variability, we considered the following on selecting fish larvae taxa for study: number of positive samples and density of these samples' occurrences, and spatial and temporal distribution of fish larvae from the CPR dataset in relation to known spawning season and locations. Therefore, generalisations based on this study concerning long-term changes in ichthyoplankton taxa must be treated with some caution.

Due to the mesh size of CPR silks, many phytoplankton species are only semiquantitatively sampled due to the small size of the organisms. There is thus a bias toward recording larger armoured flagel- lates and chain-forming diatoms, and smaller species abundance estimates from cell counts will probably be underestimated in relation to other sampling methods. However, Robinson (1970) found that the proportion of the population that is retained by the CPR silk reflects the major changes in abundance, distribution and composition (i.e. the percentage retention is roughly constant within each species even for very small-celled species).

Due to the subsurface sampling of the CPR, the survey cannot take into account long-term changes in the depth of the pycnocline. If there were significant changes to the depth of the pycnocline over a decadal time scale, this could potentially bias CPR results. Due to the lack of sufficient physical data at the same scales of this study, this potential bias could not be tested. It is worth noting, however, that the water immediately behind a large, fast-moving vessel is likely to be mixed and homogenised well below the CPR towing depth (Batten et al. 2003).

\section{Sea surface temperature}

Gridded monthly sea surface temperature (SST) data, covering the selected area and time frame, were obtained from the ICOADS 1-degree enhanced dataset provided by the NOAA-CIRES Climate Diagnostics Center (Boulder, Colorado, USA) from their website (www.cdc.noaa.gov).

\section{Surface salinity}

Gridded monthly surface salinity data for $0.111^{\circ} \times$ $0.167^{\circ}$ (latitude $\times$ longitude), covering the selected area and time frame, were obtained from the POLCOM model, from the National Oceanography Centre (NOC, Liverpool, UK).

\section{The NAO index}

The NAO index, as calculated by Hurrell (1995), is defined as the normalised winter (December to March) sea-level pressure difference between a station on the Azores and one on Iceland, and it is used to represent climate variability. The winter NAO index was provided by the Climate Analysis Section, NCAR, Boulder, Colorado, and downloaded from www.cgd.ucar.edu/cas/jhurrell/indices.html. We also used a monthly index of the NAO. 


\section{Data analysis}

Data analysis was performed using the Matlab computing language. Due to the highly skewed statistical distance of abundance values within the CPR data, these were $\log$-transformed using a $\log (x+1)$ function (Colebrook 1960). Furthermore, the CPR survey collects samples at different times of day and at locations that do not follow a regular grid. All CPR data therefore need to be regularised in time and space before being subjected to numerical analyses (Beare et al. 2003). This was undertaken on a $50 \times 50$ nautical mile $(92.6 \times 92.6 \mathrm{~km})$ grid using Inverse Distance Weighing Interpolation (Lam 1983, Legendre \& Legendre 1998). We used a search radius of 100 miles (i.e. $185.2 \mathrm{~km}$ ), and a minimum and maximum number of neighbours of 3 and 20, respectively. These values were chosen as a compromise between numerical efficiency and the need to keep the number of missing values in the interpolated grid to a minimum. CPR data also show major seasonal and diel patterns (Beare et al. 2003, Beaugrand et al. 2003b), and these were taken into account when calculating annual values. The procedure used was adapted from Beaugrand et al. (2001). The samples covering our area and period of study were grouped into day and night periods for each month and year; day/night periods were defined from calculation of the sun zenith angle at each sampling location. Spatial interpolation was performed for each month for both day and night, resulting in 24 matrices per year that were then combined to produce 45 annual matrices covering the period 1960 to 2004. The monthly gridded SST and salinity data were also combined per years to produce 45 annual matrices.

The values of each annual matrix for each parameter were averaged to produce yearly mean values of abundances of zooplankton, dinoflagellates, diatoms and each of the 5 selected ichthyoplankton taxa, as well as yearly mean values of CHLO, SST and surface salinity. Standardised anomalies in the long-term trends of every variable were calculated by removing the mean from every yearly value before reducing it by the standard deviation of that variable across $45 \mathrm{yr}$ of data.

\section{Principal component analysis}

As fluctuations in the abundance of fish larvae are likely to be influenced by several biotic and abiotic factors, correlated or independent, we used a multi- variate technique to investigate the combined effect of the 7 environmental and biological variables described above (i.e. SST, surface salinity, NAO, CHLO, abundances of diatoms, dinoflagellates and zooplankton). First, a standardised principal component analysis (PCA) was performed on the matrix of annual values (1960 to 2004) of the selected parameters for the survival and growth of the 5 selected taxa of fish larvae in the North Sea (PCA, $45 \mathrm{yr} \times 7$ variables). The aim of the PCA was to identify major patterns of year-to-year changes in the environmental composition of the North Sea.

We considered external conditions to influence larvae, adults prior to spawning and the quality and quantity of eggs produced; so in order to match the seasonality of each fish taxon with environmental conditions, we performed the PCA by using annual means for all 7 variables covering 12 mo up to the last month of larval presence. Larvae of clupeids, sandeels and gadoids were found in CPR samples throughout the year in the North Sea (Fig. 3a,b,e), and we used calendar years (January to December) to calculate annual values for all 7 variables used in the PCA. Although 2 components (January to May and June to December) can be distinguished among the clupeids, these followed similar year-to-year variability, so it was decided to retain the calendar-year grouping for this taxon too. Larvae of Atlantic mackerel and dab were only caught during a few months of the year (Fig. 3c,d). For larvae of Atlantic mackerel, the PCA was also performed on annual means calculated for the 7 variables between September the previous year and August. For larvae of dab, the PCA was also performed on annual means calculated for the 7 parameters between October the previous year and September.

Second, a PCA was performed on the matrix of monthly values of the same parameters (PCA, 540 months $\times 7$ variables). The aim of this PCA was to also consider seasonal variability of the selected variables and identify long-term monthly changes in environmental composition of the North Sea ecosystem, and their impacts on the selected taxa of fish larvae.

\section{Correlations}

In order to explore relationships and synchrony between fish larvae and environmental conditions, year-to-year fluctuations in abundance of fish larvae were correlated with the results from the PCA on the matrix of annual values. Pearson linear correlation 


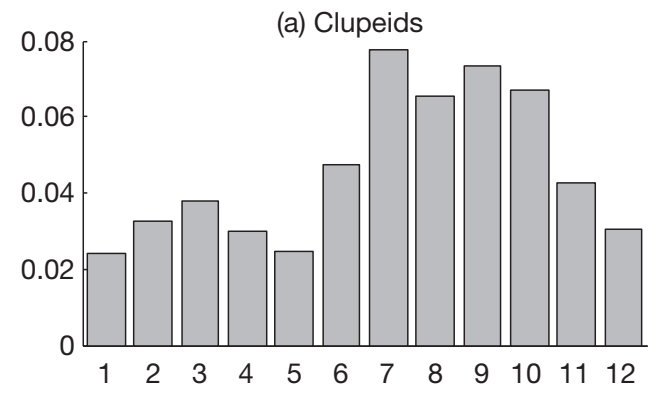

(b) Sandeels
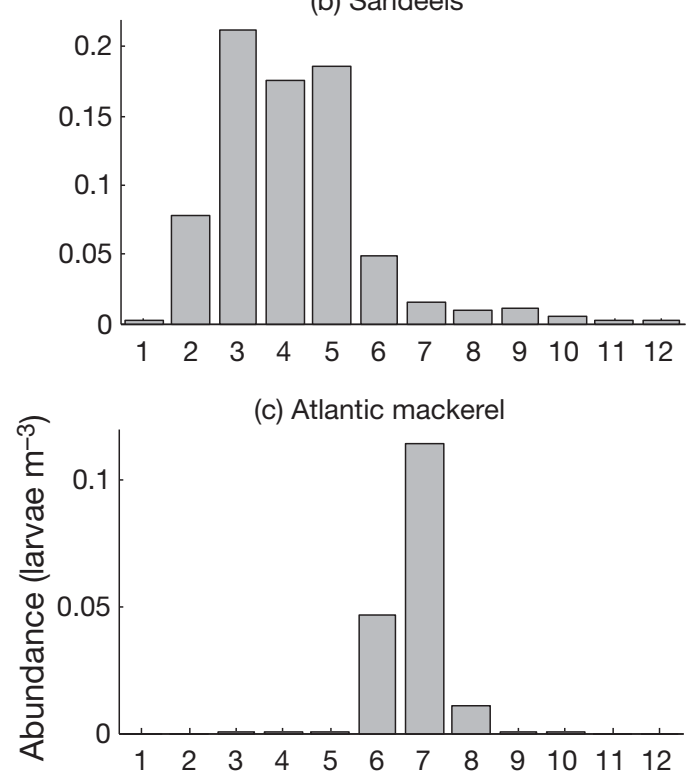

(d) Dab
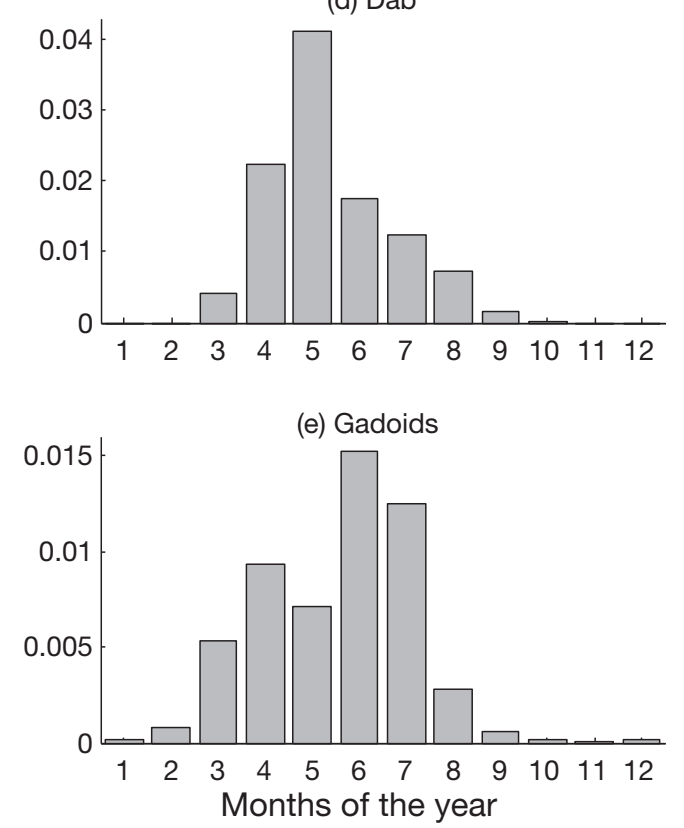

Fig. 3. Monthly abundance and seasonality of (a) clupeid, (b) sandeel, (c) Atlantic mackerel, (d) dab, and (e) gadoid larvae caught in Continuous Plankton Recorder samples, 1960 to 2004 coefficients were calculated, but to account for autocorrelation, the degrees of freedom were adjusted for autocorrelation via the modified Chelton method, with the Chatfield estimator, and the number of lags to be considered in computing autocorrelation was taken as one-fifth of the length of the time-series (Pyper \& Peterman 1998).

\section{RESULTS}

\section{PCA on the matrix of annual environmental values}

The results are shown in Table 1 (first set of loadings). The first principal component (PC1) contributes $37.59 \%$ of the variance, the greatest loadings on PC1 being zooplankton (0.53) followed by diatom abundance $(0.47)$ and dinoflagellate abundance (0.42). PC2 $(27.41 \%$ of variance) mostly reflects surface salinity $(0.54)$, followed by SST $(-0.53)$ and the NAO $(-0.44)$. PC1 is driven mainly by plankton and potential prey for fish larvae, PC2 by physical environmental and climate variables, and PC3 (11.21\% of variance) is largely driven by the NAO (0.79).

Examination of the scores plot (Fig. 4) with the first 3 principal components $(76.2 \%$ of variance) reveals 4 distinct periods of time: 1960-1976 (Period I), 1977-1982 (Period II), 1983-1996 (Period III) and 1997-2004 (Period IV). Periods I and III are similar with scores scattered in the middle of the plot. Period I is generally characterised by the highest values of $\mathrm{PC} 2$, the most important drivers being high salinity and low NAO and SST, and to a lesser extent higher zooplankton and dinoflagellate abundance and lower CHLO. Period II is characterised by low values of both PC1 and PC2, the most important drivers being low diatom and zooplankton abundance. Note that the lowest values of 6 of the 7 variables selected were measured during Period II (Fig. 5). Interestingly, Period II coincides with the GSA described in the literature and is characterised by low salinity and temperature (Belkin et al. 1998, Edwards et al. 2001, 2002). Period III indicates a recovery of the system from Period II, to a state similar to that of Period I, with high abundance of dinoflagellates and zooplankton, but also higher values of chlorophyll and the NAO (Fig. 5). Period IV is characterised by the highest values of PC1 and low values of both PC2 and PC3, and a resulting combination of high SST, chlorophyll and diatom abundance with low surface salinity and zooplankton abundance. 
Table 1. Principal component analysis (PCA) of 7 environmental and biological parameters for the period 1960 to 2004 , showing annual (yearly) values, monthly values, annual values September to August, and annual values October to September. CHLO: plankton chlorophyll index; SST: sea surface temperature; NAO: North Atlantic Oscillation. Bold values indicate the greatest loading for each principal component

\begin{tabular}{|c|c|c|c|c|c|c|c|}
\hline PCA loadings and variability by component & PC1 & PC2 & PC3 & PC4 & PC5 & PC6 & PC7 \\
\hline \multicolumn{8}{|l|}{ PCA, years (January-December) $\times$ variables } \\
\hline Diatom abundance & 0.47 & -0.05 & -0.35 & -0.60 & -0.60 & 0.08 & -0.47 \\
\hline Dinoflagellate abundance & 0.42 & 0.32 & 0.31 & 0.35 & 0.35 & 0.60 & 0.02 \\
\hline CHLO & 0.37 & -0.31 & -0.34 & 0.68 & 0.68 & -0.33 & -0.27 \\
\hline SST & 0.29 & -0.53 & -0.06 & -0.06 & -0.06 & 0.49 & 0.29 \\
\hline Surface salinity & 0.25 & 0.54 & 0.18 & 0.18 & 0.01 & -0.14 & -0.32 \\
\hline Winter NAO & 0.18 & -0.44 & 0.79 & 0.79 & -0.13 & -0.28 & -0.20 \\
\hline Zooplankton abundance & 0.53 & 0.20 & -0.03 & -0.03 & -0.14 & -0.42 & 0.68 \\
\hline Percentage total variance explained & 37.59 & 27.41 & 11.21 & 9.45 & 6.60 & 4.85 & 2.88 \\
\hline \multicolumn{8}{|l|}{ PCA, months $\times$ variables } \\
\hline Diatom abundance & 0.37 & -0.43 & 0.15 & 0.50 & -0.52 & -0.36 & -0.04 \\
\hline Dinoflagellate abundance & 0.46 & 0.33 & -0.16 & -0.11 & -0.05 & -0.17 & 0.78 \\
\hline CHLO & 0.42 & -0.22 & 0.12 & 0.32 & 0.80 & 0.04 & -0.01 \\
\hline SST & 0.42 & 0.44 & -0.19 & -0.20 & 0.02 & -0.44 & -0.60 \\
\hline Surface salinity & -0.25 & 0.47 & -0.37 & 0.76 & 0.01 & 0.06 & -0.01 \\
\hline NAO & -0.01 & 0.47 & 0.87 & 0.12 & -0.05 & 0.02 & 0.01 \\
\hline Zooplankton abundance & 0.48 & 0.09 & -0.07 & -0.02 & -0.27 & 0.81 & -0.18 \\
\hline Percentage total variance explained & 54.03 & 15.15 & 14.15 & 9.58 & 4.03 & 1.69 & 1.36 \\
\hline \multicolumn{8}{|c|}{ PCA, years (September-August) $\times$ variables; to match presence of Atlantic mackerel larvae } \\
\hline Diatom abundance & 0.47 & 0.01 & -0.32 & -0.15 & 0.65 & 0.10 & -0.45 \\
\hline Dinoflagellate abundance & 0.35 & 0.26 & 0.37 & 0.75 & -0.03 & 0.31 & -0.08 \\
\hline CHLO & 0.46 & -0.29 & -0.04 & 0.10 & -0.44 & -0.61 & -0.35 \\
\hline SST & 0.39 & -0.42 & -0.19 & -0.21 & -0.37 & 0.66 & 0.15 \\
\hline Surface salinity & 0.09 & 0.69 & 0.17 & -0.47 & -0.41 & 0.13 & -0.30 \\
\hline $\mathrm{NAO}$ & 0.08 & -0.36 & 0.83 & -0.33 & 0.24 & 0.02 & -0.12 \\
\hline Zooplankton abundance & 0.52 & 0.25 & 0.06 & -0.16 & 0.13 & -0.28 & 0.74 \\
\hline Percentage total variance explained & 41.32 & 21.62 & 14.40 & 9.16 & 6.29 & 5.40 & 1.79 \\
\hline \multicolumn{8}{|c|}{ PCA, years (October-September) $\times$ variables; to match presence of dab larvae } \\
\hline Diatom abundance & 0.48 & 0.10 & -0.33 & -0.02 & 0.67 & -0.07 & -0.46 \\
\hline Dinoflagellate abundance & 0.36 & 0.25 & 0.46 & 0.67 & -0.06 & 0.37 & -0.08 \\
\hline CHLO & 0.46 & -0.26 & -0.06 & 0.07 & -0.60 & -0.49 & -0.33 \\
\hline SST & 0.38 & -0.41 & -0.25 & -0.27 & -0.18 & 0.71 & 0.11 \\
\hline Surface salinity & 0.08 & 0.68 & 0.15 & -0.56 & -0.28 & 0.17 & -0.30 \\
\hline $\mathrm{NAO}$ & 0.11 & -0.41 & 0.77 & -0.38 & 0.27 & -0.09 & -0.10 \\
\hline Zooplankton abundance & 0.52 & 0.26 & 0.03 & -0.14 & 0.09 & -0.27 & 0.75 \\
\hline Percentage total variance explained & 41.31 & 22.19 & 14.17 & 8.58 & 6.28 & 5.53 & 1.94 \\
\hline
\end{tabular}

\section{PCA on the matrix of monthly environmental values}

These results are listed in Table 1 (second set). PC1 contributes $54.03 \%$ of the variance, the greatest loadings being zooplankton and dinoflagellate abundances (0.48 and 0.46 , respectively) followed by CHLO and SST (both 0.42). Potential prey for the fish larvae are again the major drivers of PC1. PC2 $(15.15 \%$ of variance) mainly reflects the NAO and surface salinity (both 0.47 ), followed by SST $(0.44)$ and diatom abundance $(-0.43)$. PC3 $(14.15 \%$ of variance) is largely dominated by the NAO (0.87).

Visual examination of long-term monthly changes in PC1 (Fig. 6) and PC2 (Fig. 7) also revealed distinctions between the 4 periods: Period I is characterised by generally positive PC2 anomalies and the highest values obtained in the summer months of the early 1960s period; Period II is characterised by the strongest negative PC1 and generally negative PC2 anomalies; Period III shows a recovery from Period II with rising PC1 and PC2 to average values; and Period IV is characterised by the highest PC1 and the lowest PC2 values. Similarly to the results obtained from PCA analysis performed on annual matrices, Periods II and IV are particularly distinguishable even when the seasonal variability is taken into account, indicating that interannual variability can be stronger than seasonal variability. 

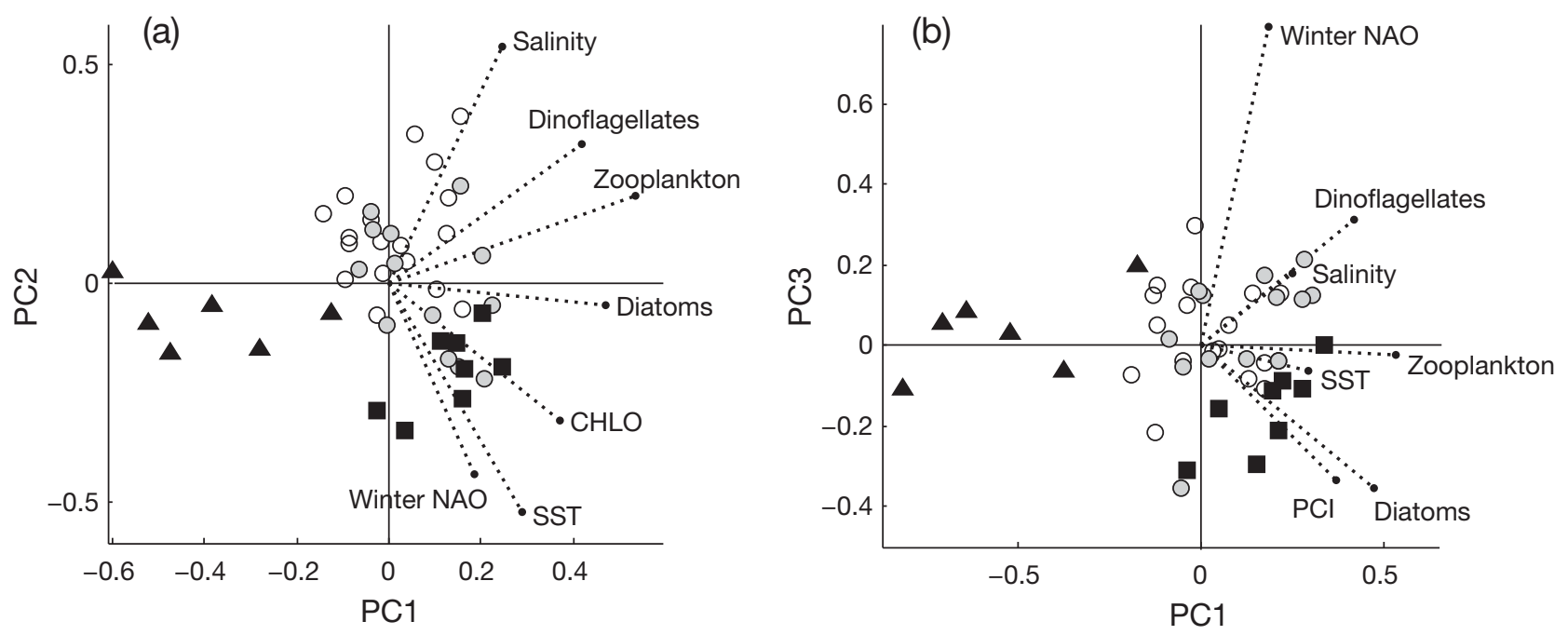

Fig. 4. Scores plot of the first 3 principal components for the analysis performed on the matrix of annual values of 7 selected environmental variables and biological parameters (PCA, $45 \mathrm{yr} \times$ variables). CHLO: plankton chlorophyll index; SST: sea surface temperature; NAO: North Atlantic Oscillation. Four distinct periods of time reflecting 3 specific ecosystem states can be seen: Periods I and III, 1960-1976 (O) and 1983-1996 (O); Period II, 1977-1982 (4); Period IV, 1997-2004 (ロ). (a) PC2 vs. PC1; (b) PC3 vs. PC1

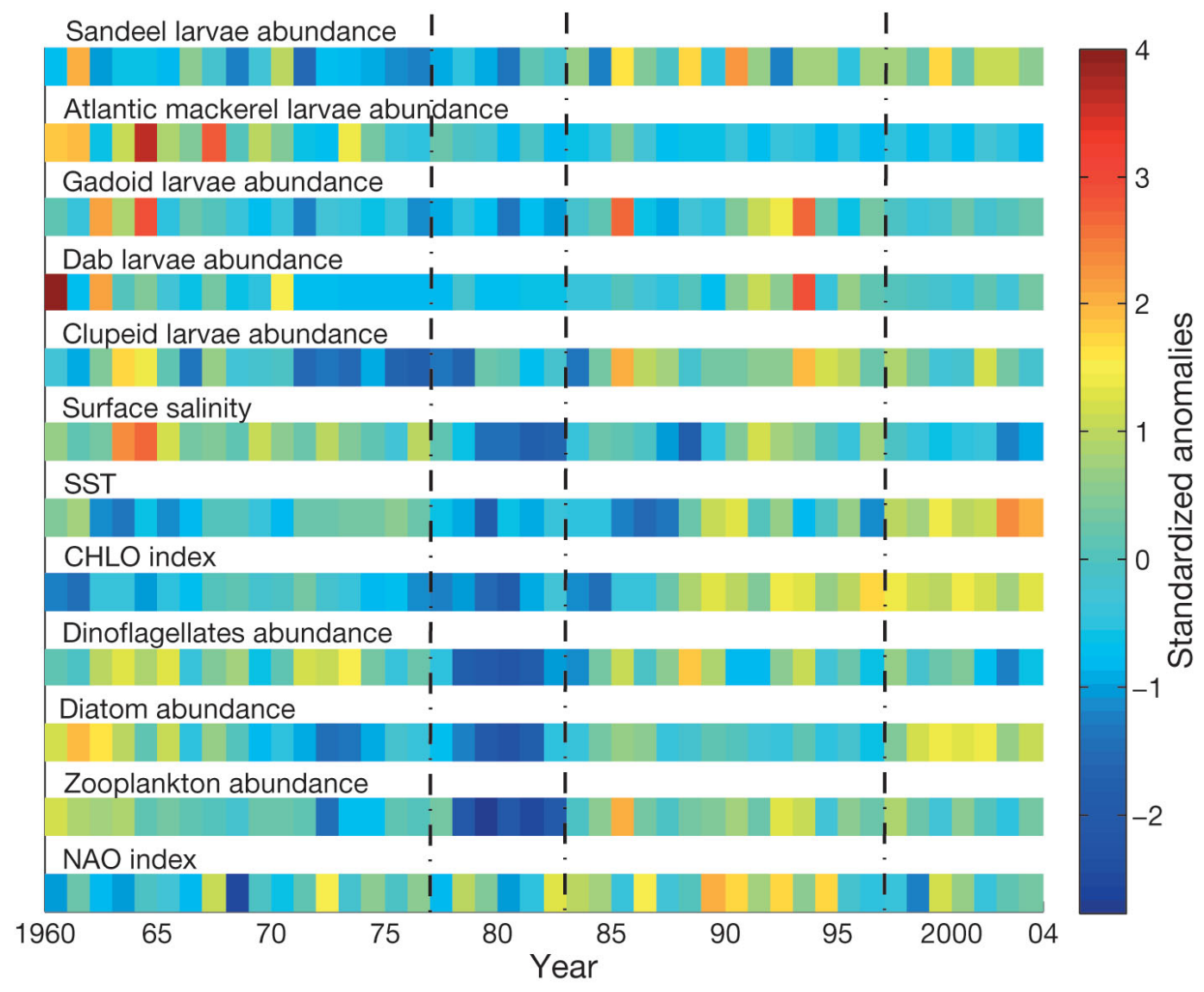

Fig. 5. Standardised anomalies in annual fluctuations in environmental variables and abundances of fish larvae, zooplankton and phytoplankton, 1960 to 2004. Dashed vertical lines show the boundaries between the 4 periods of time (I to IV) identified by the principal components analysis. SST: sea surface temperature; CHLO index: plankton chlorophyll index; NAO: North 
(a) Clupeids

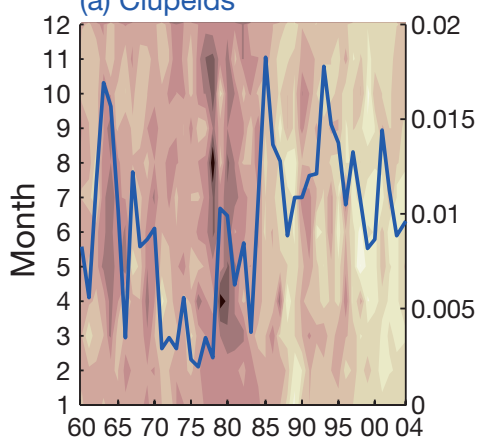

(d) Dab

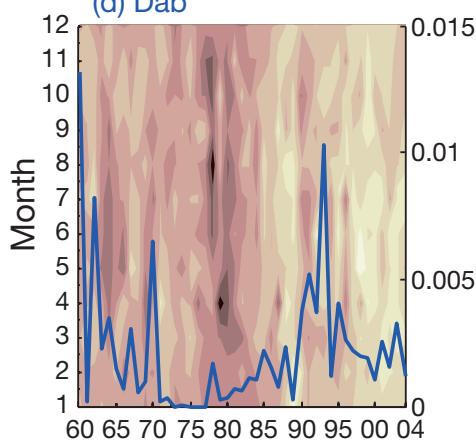

(bd) Sandeels

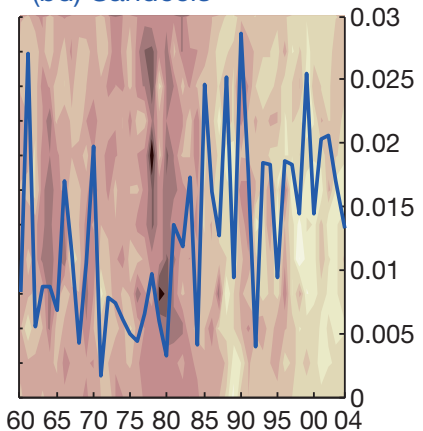

(e) Gadoids

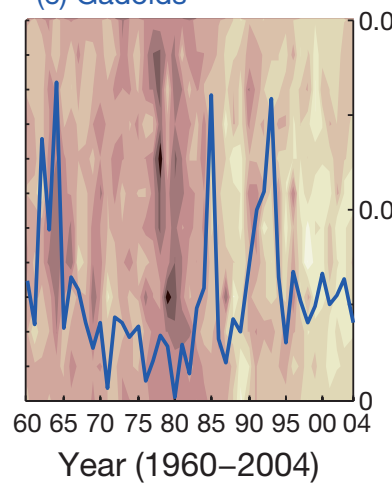

(c) Atlantic mackerel

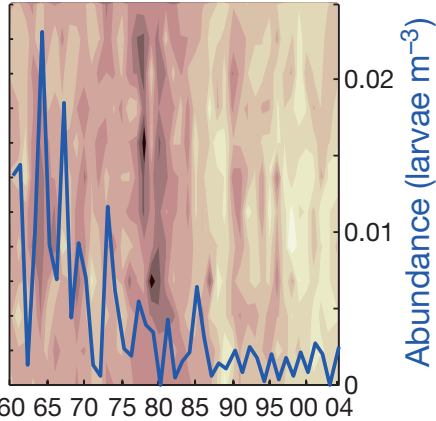

Fig. 6. Long-term monthly variability (1960 to 2004) in the 7 environmental variables used simultaneously as first principal component (PC1, 54.03\% of total variability). The blue line represents the annual abundance of (a) clupeid, (b) sandeels, (c) Atlantic mackerel, (d) dab and (e) gadoid larvae, superimposed on monthly PC1 anomalies

(a) Clupeids
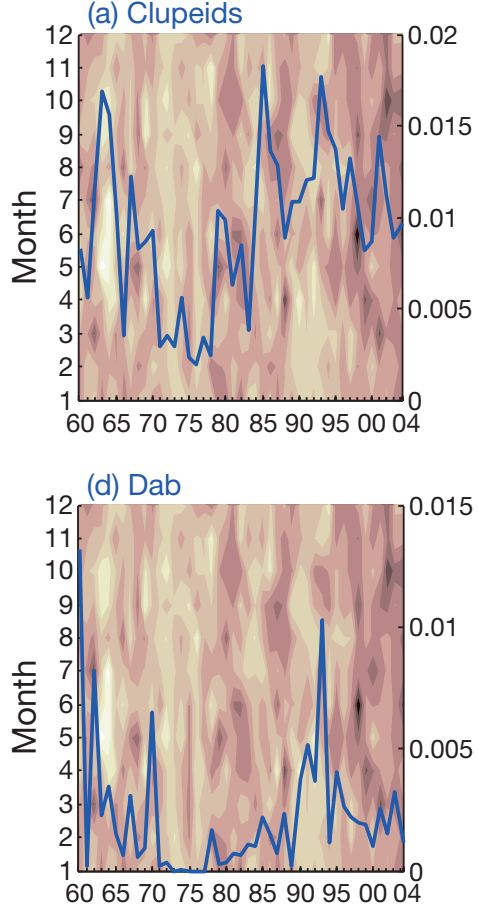

(b) Sandeels

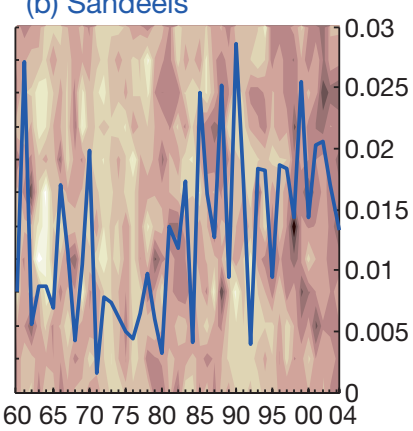

(e) Gadoids

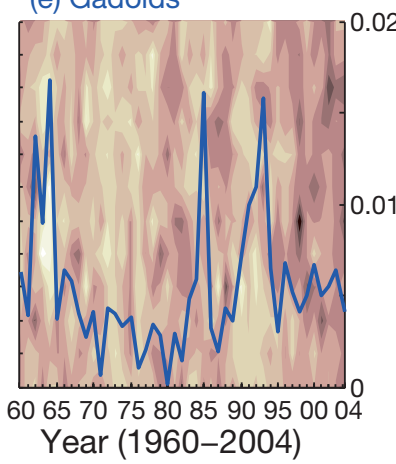

(c) Atlantic mackerel
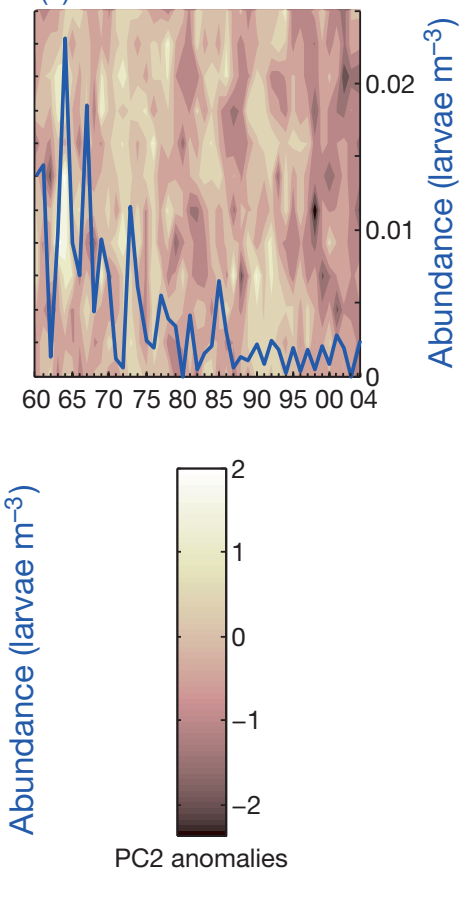

Fig. 7. Long-term monthly variability (1960 to 2004) in the 7 environmental variables used simultaneously as second principal component (PC2, 15.15\% of total variability). The blue line represents the annual abundance of (a) clupeid, (b) sandeels, (c) Atlantic mackerel, (d) dab and (e) gadoid larvae, superimposed on the monthly PC2 anomalies 
Table 2. Pearson's correlation coefficients (with associated p-values) between annual abundance of fish larvae and the first (PC1) and second principal components (PC2) resulting from analysis of the annual average to match the seasonality of fish larvae: clupeids, sandeels and gadoids (January to December), Atlantic mackerel (June to August), dab (March to September). When a statistically significant relationship was found ( ${ }^{*} 95 \%$ confidence interval), the p-value was adjusted taking into account autocorrelation; a value in bold type indicates that the relationship is still significant

\begin{tabular}{|cccccc|}
\hline & Clupeids & Sandeels & Atlantic mackerel & Dab & Gadoids \\
\hline PC1 & $0.37(0.01,0.17)^{*}$ & $0.31(0.04,0.18)^{*}$ & $-0.12(0.43)$ & $0.31(0.04,0.25)^{*}$ & $\mathbf{0 . 4 6}_{(\mathbf{0 . 0 0}, \mathbf{0 . 0 2})^{*}}$ \\
PC2 & $0.13(0.39)$ & $-0.32(0.06)$ & $\mathbf{0 . 5 4}\left(\mathbf{0 . 0 0 , 0 . 0 2 ) ^ { * }}\right.$ & $0.24(0.11)$ & $0.34(0.07)$ \\
\hline
\end{tabular}

\section{Fish larvae and PCA}

We correlated larval fish abundance with both PC1 and PC2 from the yearly analysis (Table 2). In the case of mackerel and dab, the standardised PCA was performed again on annual means of the 7 parameters selected, to match the seasonality of larval presence explained above (Table 1, third and fourth sets). There were positive correlations between PC1 and the annual abundances of 4 of the larvae (Fig. 8, clupeids: $\mathrm{R}=0.37, \mathrm{p}=0.01$; sandeels: $\mathrm{R}=0.31, \mathrm{p}=0.04$; dab: $\mathrm{R}=0.31, \mathrm{p}=0.04$; gadoids: $\mathrm{R}=0.46, \mathrm{p}<0.01$ ).
However, when autocorrelation was taken into account, only the relationship for gadoids was significant. There was no correlation between annual values of PC2 and the abundance of these larvae. These results suggest that the relationship between PC1 and fish larvae was mainly attributable to the abundance of zooplankton and phytoplankton (as indicated by their contributions to PC1).

Zooplankton abundance decreased during Period IV, particularly during the summer months July to September (Fig. 9a), coinciding with high abundances of clupeid and gadoid larvae (Fig. 3). Despite
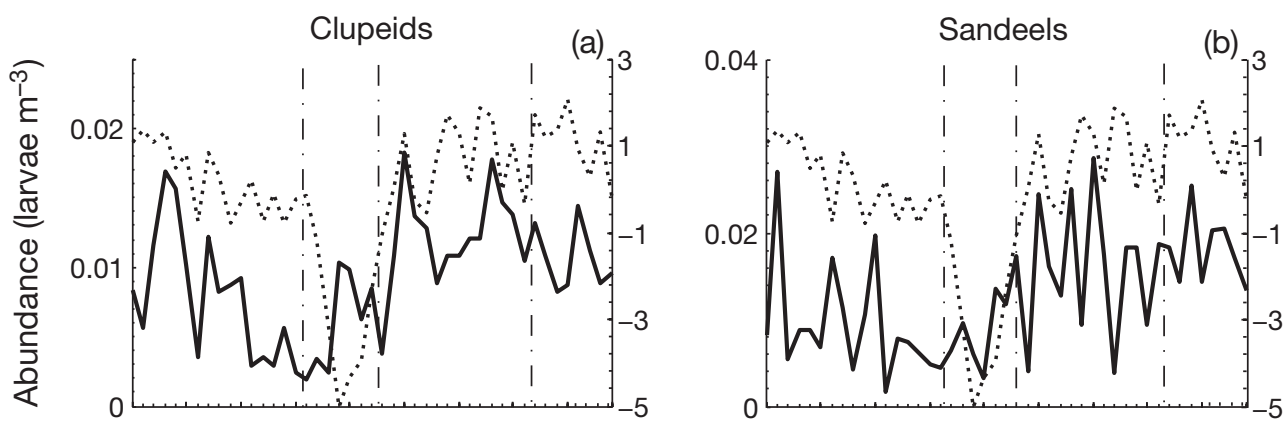

Larval abundance
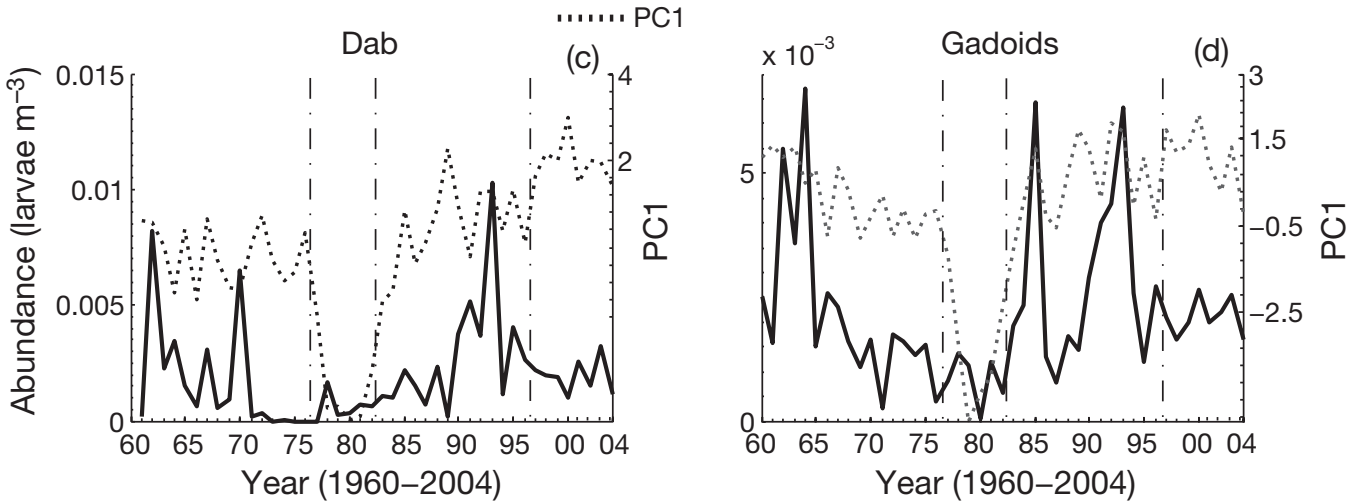

Fig. 8. Long-term variability (1960 to 2004) in larval fish abundance superimposed on changes in the PC1 for (a) clupeid, (b) sandeel, (c) dab and (d) gadoid larvae annual abundance, showing a statistically significant relationship with PC1. The standardised PCA was carried out on annual means of the 7 selected environmental variables calculated according to larval seasonality. (a,b,d) Fish larvae present all year, January to December format used. (c) Fish larvae present March to September, October one year to September next year format used. Dashed vertical lines show the boundaries between the 4 periods of time (I to IV) identified by the principal components analysis 
the drop in zooplankton abundance, clupeid larvae remained abundant, and gadoid larvae remained at average abundance, during Period IV. CHLO increased dramatically after Period II and remained high until the end of the study period (Fig. 9b). Those 4 taxa correlated to PC1 increased in abundance after Period II, but only sandeels and clupeids maintained high abundance until the end of the study, whereas gadoids and dab dropped back to average levels (Fig. 8).

Months of high phytoplankton abundance were April to October, but the phytoplankton community changed throughout the growing season. A diatom bloom in March to May was succeeded by dinoflagellates from May to October and another diatom bloom from August to October (Fig. 9b,c,d). Only diatoms increased in abundance at the same time as CHLO, indicating that these were an important contributor to the phytoplankton increase, but other species of smaller phytoplankton may have contributed too.

The trend in Atlantic mackerel larvae data behaved differently from those of the other 4 taxa, and the mackerel time-series did not show any significant relationship with PC1, but a statistically positive correlation with PC2 (Fig. 10, R = 0.54, p < 0.01), which held when autocorrelation was taken into account. The results indicate that the link between PC2 and Atlantic mackerel larvae was attributable mainly to surface salinity followed by temperature and the NAO, as indicated by their respective contribution to PC2.

The SST increase during Period IV is clear (Fig. 9e), while salinity has been decreasing particularly during spring and summer since the start of Period II (Fig. 9f). Mackerel larvae abundance dropped from Period I to reach low levels during Period II that have persisted to the end of the study.

\section{DISCUSSION}

\section{PCA results and ecosystem status}

The 4 periods of time resulting from the PCA analysis are still visible when seasonal variability is taken into consideration, indicating that long-term environmental changes are critical in defining the status of the ecosystem. Period II coincided with the first GSA or cold, low salinity event (Dickson et al. 1988); this event was followed by a second GSA or warm, high salinity event in the late 1980s to early (a) Zooplankton abundance

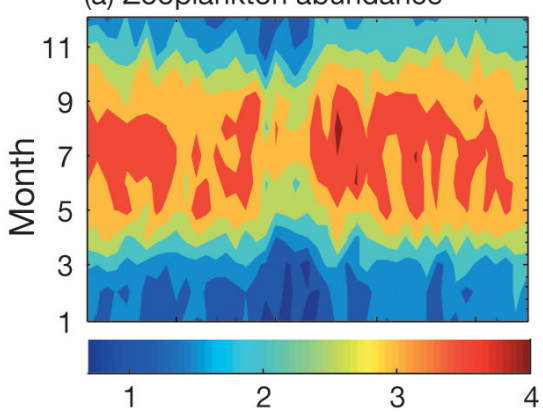

(d) Dinoflagellate abundance
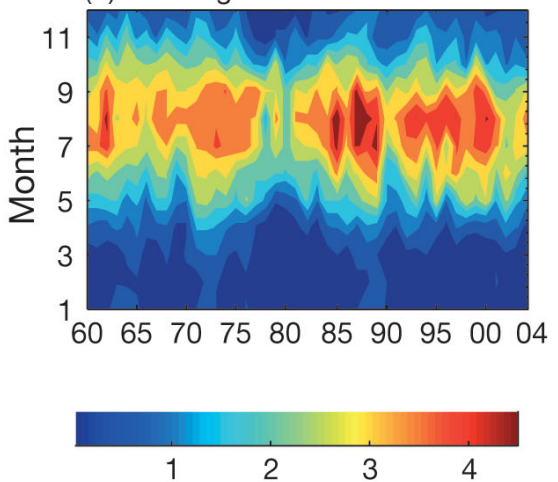

(b) CHLO

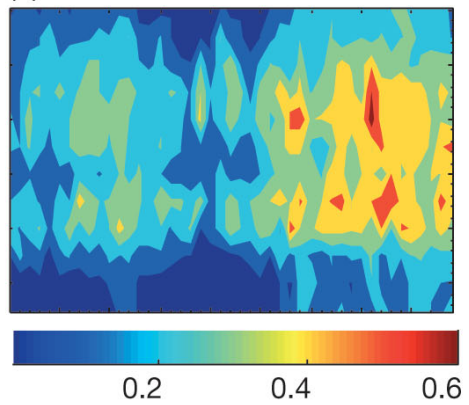

(e) SST

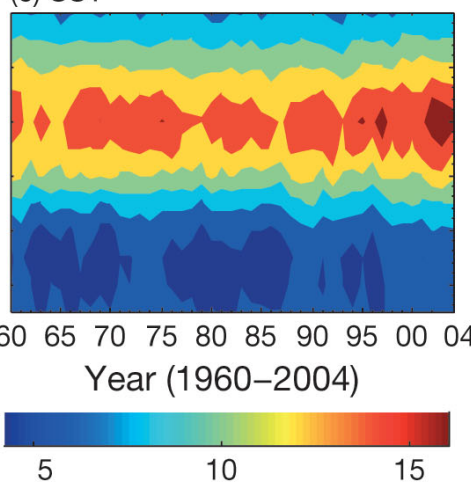

(c) Diatom abundance

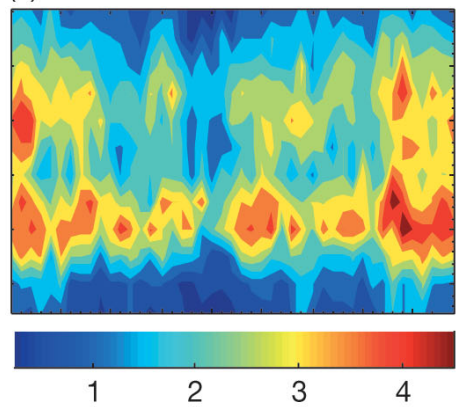

(f) Surface salinity
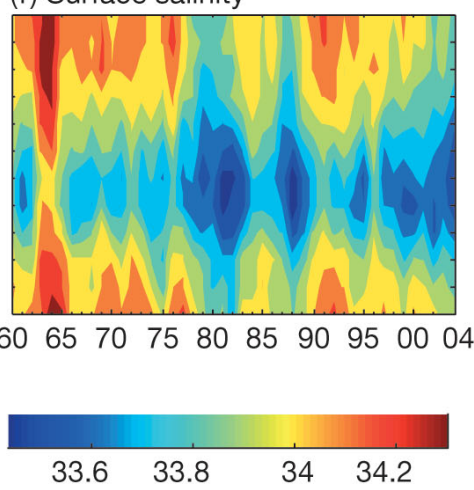

Fig. 9. Long-term monthly variability (1960 to 2004) in the main contributors to PC1 and PC2: (a) zooplankton abundance (m $\left.{ }^{-3}\right)$, (b) plankton chlorophyll (CHLO) index, (c) diatom abundance $\left(\mathrm{m}^{-3}\right)$, (d) dinoflagellate abundance ( $\left.\mathrm{m}^{-3}\right)$, (e) sea surface temperature (SST) $\left({ }^{\circ} \mathrm{C}\right)$ and (f) surface salinity (ppt) 


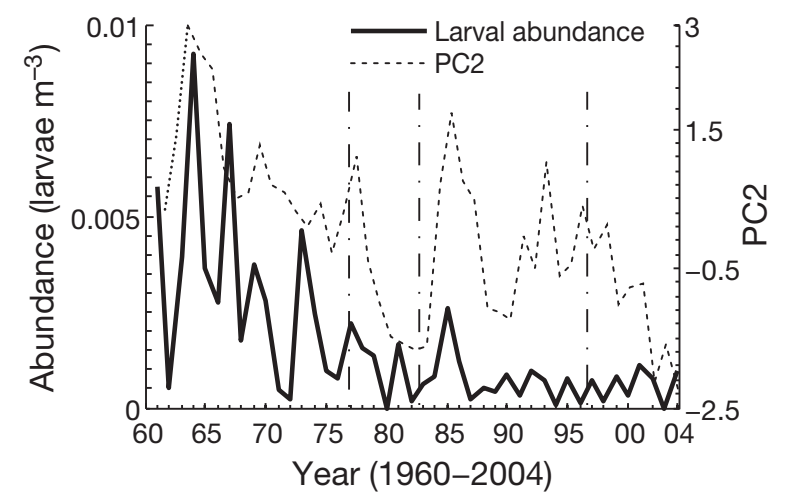

Fig. 10. Long-term variability (1960 to 2004) in Atlantic mackerel larval abundance superimposed on changes in PC2. The standardised PCA was carried out on annual means of the 7 selected environmental variables calculated according to larval seasonality. The larvae were present from June to August, September one year to August next year format used. Dashed vertical lines show the boundaries between the 4 periods of time (I to IV) identified by the principal components analysis

1990s during Period III (Belkin et al. 1998). The biological response to this later event (or combination of succeeding events) was so dramatic (Edwards et al. 2001, 2002) as to be termed 'regime shift' (Reid et al. 2001a,b, Beaugrand 2004). That period encompassed a shift in the ecosystem towards a warmer dynamic equilibrium (Reid \& Edwards 2001, Beaugrand \& Ibañez 2004). As for Period IV, the system shifted to an even warmer state but with low salinity (Fig. 5). Although SST and salinity were not the main parameters weighting on $\mathrm{PC} 1$, these nonetheless seemed to have a critical impact in shaping the general status of the North Sea ecosystem during the period studied. The NAO was also important in PC2 and explained most of PC3.

The positive correlation between the NAO and SST has been recognised in many studies (e.g. Edwards et al. 2001, Ottersen et al. 2001, Stige et al. 2006). The NAO also affects water masses, currents and circulation patterns, in turn affecting the flow of Atlantic water into the North Sea (Ottersen et al. 2001). This will in turn affect the mixed layer depth (Smayda et al. 2004), salinity levels and the flux of nutrients needed for phytoplankton growth (Edwards et al. 2001). Our PCA analyses suggest a cascading effect from climate variability to plankton via hydrographical changes within the North Sea: The NAO (as the largest contributor to PC3) appears to be an underlying driving force on the physical status of the North Sea ecosystem as described by PC2. The status of the physical environment would in turn impact on the ecological status of the North Sea ecosystem as dis- played by PC1. This is in agreement with other studies (Ottersen et al. 2004b, Pershing et al. 2004, Smayda et al. 2004) but the complexity of the mechanisms by which the NAO may influence ecological processes means that these have not yet been fully understood.

\section{Environmental variability and the survival of fish larvae}

The results illustrate the complexity of the mechanisms involved in the survival of fish larvae; many biotic and abiotic processes interact with each other, supplementing or cancelling out each other. For example, numerous studies have demonstrated that temperature has a profound effect on the physiology of fish larvae (Pörtner \& Farrell 2008). Temperature influences the rates of metabolic processes that govern energetics linked to growth, reproduction, immune competence and behaviour (Houde 1989, Batty \& Blaxter 1992, Morgan et al. 2010, Pörtner \& Peck 2010). Moreover, the influence of temperature on the physics of the environment and the subsequent impact on its organisms may be substantial. For example, Hunt Von Herbing (2002) suggested that temperature-induced changes in the physics of water flow influence swimming performance, and that this effect is particularly pronounced for small larvae in cold water, with potential implications for fish recruitment and population dynamics. Studies on the effects of temperature variation on the survival of fish larvae are numerous and have shown that the effects of temperature are species- and stage-specific (Pörtner \& Farrell 2008, Pörtner \& Peck 2010). However, Pepin (1991) reported that variations in temperature do not appear to have any significant net effect on early life-history survival because temperature effects on one life stage can be equal and opposite to its effects on another stage. Salinity plays a major role in buoyancy regulation, osmoregulation and oxygen consumption of the eggs and larvae of fish (Holliday \& Blaxter 1960, Almatar 1984).

Despite the direct effects of both temperature and salinity on fish larvae, our results suggest a potential link between clupeid, sandeel, dab and gadoid larval abundance through PC1 only, although the statistical significance of the relationship only holds for gadoids when adjusted for autocorrelation. PC1 is driven mainly by plankton indices, suggesting that for these 4 fish taxa, changes in climate, hydrography and temperature in the North Sea are more likely to affect larval survival and hence recruitment indirectly 
through the plankton rather than directly, supporting previous analyses of cod, plaice and sole larvae (Beaugrand et al. 2003a, Kirby \& Beaugrand 2009, Beaugrand \& Kirby 2010).

Water temperature controls the life cycle of many fish, so it is important that fish larvae appear at a time of food availability to ensure their survival and recruitment success (Cushing 1990, Hays et al. 2005, Daewel et al. 2011). At the same time, the timing of annual phytoplankton and zooplankton blooms is influenced by temperature, salinity and the physical properties of the water column. Warmer water leads to earlier bloom appearance (Genner et al. 2010), and successful phytoplankton production is dependent upon a good supply of nutrients to the euphotic zone (Smayda et al. 2004), itself influenced by changes in temperature and salinity which play an important role in stratification and layer mixing (Beare et al. 2002). For example, it is possible that, during the first GSA during Period II, the cold, low salinity water could have caused a seasonally persistent thermohalocline, preventing the renewal of nutrients to the euphotic zone prior to the spring bloom and hence causing its subsequent delay (Edwards et al. 2002).

In the case of Atlantic mackerel, the results show no link with PC1 but a link with PC2. PC2 is driven by physical parameters, rather than plankton indices. There are 2 main differences between mackerel and the other 4 taxa: the narrower time-window of larval presence and the migratory characteristic of mackerel.

The larvae of mackerel are caught during a very short period of time from June to August (Fig. 3). This may make mackerel more sensitive than the other fish taxa to changes in phenology in their potential preys. All potential prey for mackerel dropped in abundance during Period II (Fig. 9), but their subsequent increase during Period III was not followed by a recovery of larval abundance, and we do not see any phenological change that would lead to a temporal mismatch between the larvae and their potential preys during the period of larval presence (Figs. 9 \& 11). Preliminary visual analysis of changes in monthly spatial distribution of mackerel larvae and the selected plankton indices does not reveal a spatial mismatch either. However, the issue of matchmismatch between mackerel (and the other fish) larvae and their potential prey deserves deeper investigation using specially designed statistical methods and data of a higher spatio-temporal resolution if possible. Our results indicate that the drop and nonrecovery of mackerel larvae in the North Sea in the late 1960 s to 1970 s was not primarily caused by a decrease in prey availability, or that there was at least another critical mechanism coming into play.

The mackerel spawning in the North Sea may not be a separate natal homing stock, but are likely to be mixing with mackerel from further southwest ( $T$. Jansen unpubl.). In a simultaneous study of mackerel in the North Sea, T. Jansen et al. (unpubl.) show that a combination of stock size, fishery pressure, temperature and biomass of larger copepods preferred by mackerel larvae and adults are the likely cause of its dramatic historical development. Our findings of correlation with the salinity-driven PC2 fit well with this perception. Salinity might be seen as a marker for water masses preferred by mackerel as a result of zooplankton abundance and temperature. Prey availability is a driver of mackerel recruitment in the Northwest Atlantic (Castonguay et al. 2008). In the case of Northeast Atlantic mackerel, the path from food to spawning stock size in the North Sea is more complex, because it involves a dynamic migration pattern combined with a possible food-recruitment link. Larval production and recruitment should, as a consequence of the dynamic spatial behaviour, be analysed over the whole spawning area from the Bay of Biscay, west of the British Isles and into the North Sea.

\section{Species reaction and adaptation to environmental variability}

The changes linked to the GSA events affected many taxa and resulted in reorganisation within the plankton communities. Moreover, the analysis by Pitois \& Fox (2006) shows that mean zooplankton size peaked during Period II, then dropped in the late 1980s. Beaugrand et al. (2003a) reported that the regime shift radically changed the food environment

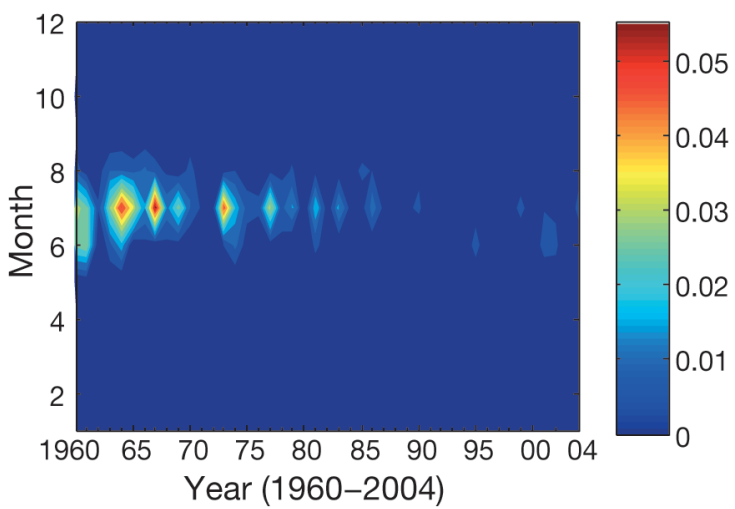

Fig. 11. Long-term monthly variability (1960 to 2004) in the abundance of mackerel larvae $\left(\mathrm{m}^{-3}\right)$ from the Continuous Plankton Recorder dataset 
for larval cod in a way that reduced the survival of young fish. The taxa studied here seemed to fare differently during each period, suggesting that different species react differently to environmental changes and in particular to changes in the availability and quality of prey.

The diet of the larvae of each taxon analysed here have been studied in detail before. After hatching, larvae start feeding on phytoplankton and copepod nauplii and gradually switch to copepodites as they grow. In the case of sandeels, the literature indicates that early larval stages $<8 \mathrm{~mm}$ long feed exclusively on phytoplankton (Monteleone \& Peterson 1986). Although the prey items are similar for all 5 taxa, the relative proportions of prey from gut analysis vary from fish to fish and study to study (Last 1980, Checkley 1982, Cohen \& Lough 1983, Fossum 1983, Peterson \& Ausubel 1984, Munk \& Kiørboe 1985, Simonsen et al. 2006). Fish larvae caught by the CPR are very small; Johnson (1977) reported that the larvae of Atlantic mackerel caught by the CPR were $<7 \mathrm{~mm}$ long, on average $5 \mathrm{~mm}$. Such larvae are very young and likely to feed on the smallest prey available, such as phytoplankton and copepod eggs and nauplii. The zooplankton index used here has been corrected for undersampling by the $\mathrm{CPR}$, but it still only comprises the larger copepodite and adults and does not include naupliar stages. For lack of better information, it seems reasonable to assume that abundances of copepod nauplii are linked to similarly high abundances of copepods during summer, as shown here. Our results agree with the results of other studies of larval diet, except in the case of Atlantic mackerel. As suggested above, however, it might be that, in the case of mackerel, a migratory species, other factors linked to hydrographic variability were playing a prominent part in influencing their spawning in the North Sea.

The increase in phytoplankton biomass in the North Sea from the late 1980s (Fig. 9b) has been attributed to increases in SST (Edwards et al. 2001). This increase seems to have benefitted clupeid, sandeel, dab and gadoid larvae, all of which increased markedly in abundance at the start of Period III (Fig. 5). The abundance of zooplankton also increased dramatically at the same time, but the trend was reversed in the early 1990s and zooplankton abundance has been decreasing ever since. Clupeid abundance remained high as that of zooplankton decreased, suggesting that clupeid larvae do adapt to changes in their prey environment and can switch between different prey, depending on availability. The ability of fish larvae to switch their diet to lower trophic levels when necessary has been reported previously by Malzahn \& Boersma (2009). In their comparative study on sandeel and dab larvae, they found that for dab, smaller size classes can switch to lower trophic levels and handle the greater variability of prey quality better than sandeels, and they suggested that although vulnerable to changing prey fields, fish larvae may be able to react flexibly as they evolve in a fast-changing environment. This vulnerability and flexibility seems to be species-specific, and the more adaptable larvae should be able to survive when the quality of the feeding environment decreases, by switching to lower trophic level preys such as phytoplankton, microzooplankton, protozoans and small metazoans. Indeed, there is growing evidence that microzooplankton, including the protozoans, play an important role and are regularly used as prey by fish larvae or at least to substitute their commonly accepted crustacean-based diet (Fukami et al. 1999, de Figueiredo et al. 2005, Pedersen \& Fossheim 2008).

\section{Predicting species-specific response from climate variability}

The PCA shows that the availability of prey seems to be the main driver for the survival of fish larvae under various environmental conditions. The cascading effects of warming temperature, through the plankton ecosystem, in recent decades has been demonstrated in many previous studies, and the results here similarly suggest that this indirect effect of temperature on the survival of larval fish is the main pathway of climate change effects on fish recruitment. In the case of Atlantic mackerel, and possibly other migratory species, however, hydrographic features seem to play a more dominant role by controlling migration of the adults to their spawning ground (Reid et al. 2001a, T. Jansen et al. unpubl.). Nevertheless, these 2 effects are not mutually exclusive. For example, Munk et al. (2009) stated that the main spawning locations of fish such as cod, haddock, plaice, long rough dab and sandeel in the North Sea are linked to recurrent hydrographic features, and Castonguay et al. (2008) showed that Atlantic mackerel recruitment is heavily dependent on the production of the copepod nauplii that contribute extensively to the diet of its larvae. In addition, factors not considered here may also play an important role. Among such factors are spawning stock size, reproduction, including spawning location and time (Ellertsen et al. 1989, Hutchings \& Myers 1994), transport of eggs and larvae outside their 
spawning/nursery grounds (Hinrichsen et al. 2001, Ottersen et al. 2004a), predation on eggs and larvae (Bailey \& Houde 1989, Kempf et al. 2009) and competition between species for limited food resources (Kane 1984). These results further illustrate the complexity of the mechanisms involved in the appearance and survival of fish larvae.

There is, however, another complication, that of the impact of a fishery. Overfishing not only reduces stock abundance, but also renders stocks more sensitive to additional stress from either fishing pressure or environmental variability via bottom-up control (Brander 2005, Ottersen et al. 2006, Anderson et al. 2008, Perry et al. 2010). The effects of climate and fishing interact with each other in such a manner that climate may cause failure of a fishery management plan, while exploitation may disrupt the ability of a fish population to withstand or adapt to climate change (Planque et al. 2010).

The CPR fish larvae dataset with its extensive spatio-temporal coverage clearly offers a unique opportunity to investigate the responses of fish populations to past changes in climate, including abrupt changes such as regime shifts. The results here show that responses to environmental variability are speciesspecific, and with further in-depth analysis, it might be possible to develop species-specific indices of 'larval survival potential' under specific environmental conditions and ecosystem states resulting from climate change. Larval studies provide an indication of mortality and survival, and hence of the potential size of a future fish stock, and egg surveys and stock assessment indicate the size of the present spawning stock (Fives et al. 2001). There is, therefore, a strong indication that the 2 types of data should complement each other. Preliminary results from studies by C. P. Lynam et al. (unpubl.) and Jansen et al. (2012), working with the CPR fish larvae dataset linked with stock assessment data on sandeel and Atlantic mackerel, respectively, are encouraging, and suggest that the CPR data, although not a replacement for traditional stock assessment tools, is a valuable source of information. The interacting effects of fishing (topdown) and climate (bottom-up) make the prediction of the response of marine fish to climate change scenarios an immense challenge for fisheries research. The complexity of such interactions and the mechanisms involved in these processes might make it unrealistic to separate empirically climate- from fishery-induced effects, and supports studies orientated towards understanding the interactions between climate and fishing (Perry et al. 2010, Planque et al. 2010).
Acknowledgements. We thank the staff of the Sir Alister Hardy Foundation for Ocean Science and the masters and crews of the ships that tow CPRs on a voluntary basis. Without their dedication over the years, these analyses would not have been possible. We also thank J. Holt for providing salinity data from the POLCOM model and C. Fox for his work developing the initial project proposal. The analysis was funded by Defra UK grant MF1101.

\section{LITERATURE CITED}

Almatar SM (1984) Effects of acute changes in temperature and salinity on the oxygen uptake of larvae of herring (Clupea harengus) and plaice (Pleuronectes platessa). Mar Biol 80:117-124

Anderson CNK, Hsieh CH, Sandin SA, Hewitt R and others (2008) Why fishing magnifies fluctuations in fish abundance. Nature 452:835-839

$>$ Bailey KM, Houde ED (1989) Predation on eggs and larvae of marine fishes and the recruitment problem. Adv Mar Biol 25:1-83

> Batten SD, Clark R, Flinkman J, Hays G and others (2003) CPR sampling: the technical background, materials and methods, consistency and comparability. Prog Oceanogr 58:193-215

Batty RS, Blaxter JHS (1992) The effect of temperature on the burst swimming performance of fish larvae. J Exp Biol 170:187-201

> Beare DJ, Batten S, Edwards M (2002) Prevalence of boreal Atlantic, temperate Atlantic and neritic zooplankton in the North Sea between 1958 and 1998 in relation to temperature, salinity, stratification intensity and Atlantic inflow. J Sea Res 48:29-49

> Beare DJ, Batten SD, Edwards M, McKenzie E, Reid PC, Reid DG (2003) Summarizing spatial and temporal information in CPR data. Prog Oceanogr 58:217-233

> Beaugrand G (2004) The North Sea regime shift: evidence, causes, mechanisms and consequences. Prog Oceanogr 60:245-262

- Beaugrand G, Ibañez F (2004) Monitoring marine plankton ecosystems. II. Long-term changes in North Sea calanoid copepods in relation to hydro-climatic variability. Mar Ecol Prog Ser 284:35-47

> Beaugrand G, Kirby R (2010) Climate, plankton and cod. Glob Change Biol 16:1268-1280

> Beaugrand G, Ibañez F, Lindley JA (2001) Geographical distribution and seasonal and diel changes in the diversity of calanoid copepods in the North Atlantic and North Sea. Mar Ecol Prog Ser 219:189-203

Beaugrand G, Brander KM, Lindley JA, Souissi S, Reid PC (2003a) Plankton effect on cod recruitment in the North Sea. Nature 426:661-664

Beaugrand G, Ibañez F, Lindley JA (2003b) An overview of statistical methods applied to CPR data. Prog Oceanogr 58:235-262

Belkin IM, Levitus S, Antonov J, Malmberg SA (1998) 'Great Salinity Anomalies' in the North Atlantic. Prog Oceanogr 41:1-68

Brander KM (1992) A re-examination of the relationship between cod recruitment and Calanus finmarchicus in the North Sea. ICES Mar Sci Symp 195:393-401

> Brander KM (2005) Cod recruitment is strongly affected by climate when stock biomass is low. ICES J Mar Sci 62: 339-343 
Brander K, Mohn R (2004) Effect of the North Atlantic Oscillation on recruitment of Atlantic cod (Gadus morhua). Can J Fish Aquat Sci 61:1558-1564

Brander KM, Dickson RR, Shepherd JG (2001) Modelling the timing of plankton production and its effect on recruitment of cod (Gadus morhua). ICES J Mar Sci 58: 962-966

> Brander KM, Dickson RR, Edwards M (2003) Use of Continuous Plankton Recorder information in support of marine management: applications in fisheries, environmental protection, and in the study of ecosystem response to environmental change. Prog Oceanogr 58:175-191

> Brierley AS, Kingsford M (2009) Impacts of climate change on marine organisms and ecosystems. Curr Biol 19: R602-R614

Castonguay M, Plourde S, Robert D, Runge JA, Fortier L (2008) Copepod production drives recruitment in a marine fish. Can J Fish Aquat Sci 65:1528-1531

Checkley DMJ (1982) Selective feeding by Atlantic herring (Clupea harengus) larvae on zooplankton in natural assemblages. Mar Ecol Prog Ser 9:245-253

Cheung WWL, Lam VWY, Sarmiento JL, Kearney K, Watson R, Pauly D (2009) Projecting global marine biodiversity impacts under climate change scenarios. Fish Fish 10: 235-251

> Clark DR, Aazem KV, Hays GC (2001) Zooplankton abundance and community structure over a $4000 \mathrm{~km}$ transect in the North-east Atlantic. J Plankton Res 23:365-372

Cohen RE, Lough RG (1983) Prey field of larval herring Clupea harengus on a continental shelf spawning area. Mar Ecol Prog Ser 10:211-222

Colebrook JM (1960) Continuous plankton records: methods of analysis, 1950-59. Bull Mar Ecol 5:51-64

Colebrook JM (1975) The continuous plankton recorder survey: automatic data processing methods. Bull Mar Ecol 8: 123-142

> Coombs SH (1975) Continuous plankton records show fluctuations in larval fish abundance during 1948-72. Nature 258:134-136

Cushing DH (1984) The gadoid outburst in the North Sea. J Cons Int Explor Mer 41:159-166

$>$ Cushing DH (1990) Plankton production and year-class strength in fish populations: an update of the match/ mismatch hypothesis. Adv Mar Biol 26:249-293

> Daewel U, Peck MA, Schrum C (2011) Life history strategy and impacts of environmental variability on early life stages of two marine fishes in the North Sea: an individual-based modelling approach. Can J Fish Aquat Sci 68:426-443

de Figueiredo GM, Nash RDM, Montagnes DJS (2005) The role of the generally unrecognised microprey source as food for larval fish in the Irish Sea. Mar Biol 148:395-404

> Dickson RR, Meincke J, Malmberg SA, Lee AJ (1988) The 'great salinity anomaly' in the northern North Atlantic 1968-1982. Prog Oceanogr 20:103-151

> Drinkwater KF, Belgrano A, Borja A, Conversi A and others (2003) The response of marine ecosystems to climate variability associated with the North Atlantic Oscillation. Geophys Monogr 134:211-233

Edwards M, Helaouet P, Halliday N, Beaugrand G and others (2011) Fish larvae atlas of the NE Atlantic. Results from the continuous plankton recorder survey 19482005. Sir Alister Hardy Foundation for Ocean Science, Plymouth

Edwards M, Richardson AJ (2004) Impact of climate change on marine pelagic phenology and trophic mismatch. Nature 430:881-884

- Edwards M, Reid P, Planque B (2001) Long-term and regional variability of phytoplankton biomass in the Northeast Atlantic (1960-1995). ICES J Mar Sci 58:39-49

Edwards M, Beaugrand G, Reid PC, Rowden AA, Jones MB (2002) Ocean climate anomalies and the ecology of the North Sea. Mar Ecol Prog Ser 239:1-10

Ellertsen B, Fossum P, Solemdal P, Sundby S (1989) Relation between temperature and survival of eggs and firstfeeding larvae of northeast Artic cod (Gadus morhua L.). Rapp P-V Reùn Cons Int Explor Mer 191:209-219

Erftemeijer PLA, van Beek JKL, Bolle LJ, Dickey-Collas M, Los HFJ (2009) Variability in transport of fish eggs and larvae. I. Modelling the effects of coastal reclamation. Mar Ecol Prog Ser 390:167-181

> Fives JM, Acevedo S, Lloves M, Whitaker A, Robinson M, King PA (2001) The distribution and abundance of larval mackerel, Scomber scombrus L., horse mackerel, Trachurus trachurus (L.), hake, Merluccius merluccius (L.), and blue whiting, Micromesistius poutassou (Risso, 1826) in the Celtic Sea and west of Ireland during the years 1986, 1989 and 1992. Fish Res 50:17-26

Fossum P (1983) Digestion rate of food particles in the gut of larval herring (Clupea harengus L.). FiskDir Skr Ser HavUnders 17:347-357

Fukami K, Watanabe A, Fujita S, Yamaoka K, Nishijima T (1999) Predation on naked protozoan microzooplankton by fish larvae. Mar Ecol Prog Ser 185:285-291

- Genner MJ, Halliday NC, Simpson SD, Southward AJ, Hawkins SJ, Sims DW (2010) Temperature-driven phenological changes within a marine larval fish assemblage. J Plankton Res 32:699-708

Hays GC, Richardson AJ, Robinson C (2005) Climate change and marine plankton. Trends Ecol Evol 20:337-344

Hillgruber N, Kloppmann M, Wahl E, von Westernhagen $\mathrm{H}$ (1997) Feeding of larval blue whiting and Atlantic mackerel: a comparison of foraging strategies. J Fish Biol 51: 230-249

Hinrichsen HH, St John MA, Aro E, Grønkjær P, Voss R (2001) Testing the larval drift hypothesis in the Baltic Sea: retention versus dispersion caused by wind-driven circulation. ICES J Mar Sci 58:973-984

Holliday FG, Blaxter JHS (1960) The effects of salinity on the developing eggs and larvae of the herring. J Mar Biol Ass UK 39:591-603

> Horwood J, Cushing D, Wyatt T (2000) Planktonic determination of variability and sustainability of fisheries. J Plankton Res 22:1419-1422

Houde ED (1989) Comparative growth, mortality, and energetics of marine fish larvae: temperature and implied latitudinal effects. Fish Bull US 87:471-495

> Houde ED (2008) Emerging from Hjort's shadow. J Northwest Atl Fish Sci 41:53-70

> Hufnagl M, Peck MA (2011) Physiological individual-based modelling of larval Atlantic herring (Clupea harengus) foraging and growth: insights on climate-driven life-history scheduling. ICES J Mar Sci 68:1170-1188

Hunt Von Herbing I (2002) Effects of temperature on larval fish swimming performance: the importance of physics to physiology. J Fish Biol 61:865-876

Hurrell JW (1995) Decadal trends in the North Atlantic Oscillation: regional temperatures and precipitation. Science 269:676-679

Hurrell JW, Kushnir Y, Ottersen G, Visbeck M (2003) An 
overview of the North Atlantic Oscillation. Geophys Monogr 134:1-35

- Hutchings JA, Myers RA (1994) Timing of cod reproduction: interannual variability and the influence of temperature. Mar Ecol Prog Ser 108:21-31

Jansen T, Gislason H (2011) Temperature affects the timing of spawning and migration of North Sea mackerel. Cont Shelf Res 31:64-72

Jansen T, Kristiansen K, Payne M, Edwards M, Schrum C, Pitois S (2012) Long-term retrospective analysis of mackerel spawning in the North Sea: a new time series and modeling approach to CPR. PLoS ONE X 7(6):e38758

$>$ John EH, Batten SD, Harris RP, Hays GC (2001) Comparison between zooplankton data collected by the Continuous Plankton Recorder survey in the English Channel and by WP-2 nets at station L4, Plymouth (UK). J Sea Res 46: 223-232

Johnson PO (1977) A review of spawning in the North Atlantic mackerel, Scomber scrombrus L. Fish Res Tech Rep 37. MAFF, Lowestoft

Kane J (1984) The feeding habits of co-occurring cod and haddock larvae from Georges Bank. Mar Ecol Prog Ser 16:9-20

> Kempf A, Floeter J, Temming A (2009) Recruitment of North Sea cod (Gadus morhua) and Norway pout (Trisopterus esmarkii) between 1992 and 2006: the interplay between climate influence and predation. Can J Fish Aquat Sci 66:633-648

Kirby RR, Beaugrand G (2009) Trophic amplification of climate warming. Proc Biol Sci 276:4095-4103

> Lam N (1983) Spatial interpolation methods: a review. Am Cartographer 10:129-149

Last JM (1980) The food of twenty species of fish larvae in the west-central North Sea. MAFF, Directorate of Fisheries Research, Lowestoft

Legendre P, Legendre L (1998) Spatial analysis. In: Legendre P, Legendre L (eds) Numerical ecology: Developments in environmental modelling. Elsevier, Amsterdam

Lindley JA, Halliday NC, Stevens DP (2007) Fish data from the Continuous Plankton Recorder survey. ICES CM 2007 (E:24). ICES, Copenhagen

> Malzahn AM, Boersma M (2009) Trophic flexibility in larvae of two fish species (lesser sandeel, Ammodytes marinus and dab, Limanda limanda). Sci Mar 73:131-139

Monteleone DM, Peterson WT (1986) Feeding ecology of American sand lance Ammodytes americanus larvae from Long Island Sound. Mar Ecol Prog Ser 30:133-143

- Morgan MJ, Rideout RM, Colbourne EB (2010) Impact of environmental temperature on Atlantic cod Gadus morhua energy allocation to growth, condition and reproduction. Mar Ecol Prog Ser 404:185-195

Munk P, Kiørboe T (1985) Feeding behaviour and swimming activity of larval herring (Clupea harengus) in relation to density of copepod nauplii. Mar Ecol Prog Ser 24:15-21

Munk P, Fox CJ, Bolle LJ, van Damme CJG, Fossum P, Kraus G (2009) Spawning of North Sea fishes linked to hydrographic features. Fish Oceanogr 18:458-469

Myers RA (1998) When do environment-recruitment correlations work? Rev Fish Biol Fish 8:285-306

Ottersen G, Planque B, Belgrano A, Post E, Reid PC, Senseth NC (2001) Ecological effects of the North Atlantic Oscillation. Oecologia 128:1-14

Ottersen G, Alheit J, Drinkwater K, Friedland K, Hagen E, Stenseth NC (2004a) The responses of fish populations to ocean climate fluctuations. In: Stenseth NC, Ottersen G, Hurrell J, Belgrano A (eds) Marine ecosystems and cli- mate variation: the North Atlantic. Oxford University Press, Oxford, p 73-94

Ottersen G, Stenseth NC, Hurrell JW (2004b) Climatic fluctuations and marine systems: a general introduction to the ecological effects. In: Stenseth NC, Ottersen G, Hurrell J, Belgrano A (eds) Marine ecosystems and climate variation: the North Atlantic. Oxford University Press, Oxford, p 3-14

> Ottersen G, Hjermann DØ, Stenseth NC (2006) Changes in spawning stock structure strengthen the link between climate and recruitment in a heavily fished cod (Gadus morhua) stock. Fish Oceanogr 15:230-243

> Pedersen T, Fossheim M (2008) Diet of 0-group stages of capelin (Mallotus villosus), herring (Clupea harengus) and cod (Gadus morua) during spring and summer in the Barents Sea. Mar Biol 153:1037-1046

$>$ Pepin P (1991) Effect of temperature and size on development, mortality, and survival rates of the pelagic early life history stages of marine fish. Can J Fish Aquat Sci 48: 503-518

Perry AL, Low PJ, Ellis JR, Reynolds JD (2005) Climate change and distribution shifts in marine fishes. Science 308:1912-1915

Perry RI, Cury P, Brander K, Jennings S, Möllmann C, Planque B (2010) Sensitivity of marine systems to climate and fishing: concepts, issues and management responses. J Mar Syst 79:427-435

Pershing AJ, Greene CH, Planque B, Fromentin JM (2004) The influences of climate variability on North Atlantic zooplankton populations. In: Stenseth NC, Ottersen G, Hurrell J, Belgrano A (eds) Marine ecosystems and climate variation: the North Atlantic. Oxford University Press, Oxford, p 59-69

Peterson WT, Ausubel SJ (1984) Diets and selective feeding by larvae of Atlantic mackerel Scomber scombrus on zooplankton. Mar Ecol Prog Ser 17:65-75

Pitois SG, Fox CJ (2006) Long-term changes in zooplankton biomass concentration and mean size over the Northwest European shelf inferred from Continuous Plankton Recorder data. ICES J Mar Sci 63:785-798

> Planque B, Fromentin JM, Cury P, Drinkwater KF, Jennings S, Perry RI, Kifani S (2010) How does fishing alter marine populations and ecosystems sensitivity to climate? J Mar Syst 79:403-417

> Platt T, Fuentes-Yaco C, Frank KT (2003) Spring algal bloom and larval fish survival. Nature 423:398-399

Pörtner HO, Farrell AP (2008) Physiology and climate change. Science 322:690-692

Pörtner HO, Peck MA (2010) Climate change effects on fishes and fisheries: towards a cause-and-effect understanding. J Fish Biol 77:1745-1779

Pyper BJ, Peterman R (1998) Comparison of methods to account for autocorrelation in correlation analyses of fish data. Can J Fish Aquat Sci 55:2127-2140

> Reid PC, Edwards M (2001) Long-term changes in the pelagos, benthos and fisheries of the North Sea. Senckenb Marit 31:107-115

> Reid PC, Battle EJV, Batten SD, Brander KM (2000) Impacts of fisheries on plankton community structure. ICES J Mar Sci 57:495-502

> Reid PC, Borges Mde F, Svendsen E (2001a) A regime shift in the North Sea circa 1988 linked to changes in the North Sea horse mackerel fishery. Fish Res 50:163-171

> Reid PC, Holliday NP, Smyth TJ (2001b) Pulses in the eastern margin current and warmer water off the north west 
European shelf linked to North Sea ecosystem changes. Mar Ecol Prog Ser 215:283-287

Reid PC, Colebrook JM, Matthews JBL, Aiken J (2003) The continuous plankton recorder: concepts and history, from plankton indicator to undulating recorders. Prog Oceanogr 58:117-173

Richardson AJ, Schoeman DS (2004) Climate impact on plankton ecosystems in the Northeast Atlantic. Science 305:1609-1612

Robert D, Castonguay M, Fortier L (2008) Effects of intraand inter-annual variability in prey field on the feeding selectivity of larval Atlantic mackerel (Scomber scombrus). J Plankton Res 30:673-688

Robinson GA (1970) Continuous plankton records: Variation in the seasonal cycle of phytoplankton in the north Atlantic. Bull Mar Ecol 6:333-345

Rose GA (2005) On distributional responses of North Atlantic fish to climate change. ICES J Mar Sci 62:1360-1374

Simonsen CS, Munk P, Folkvord A, Petersen SA (2006) Feeding ecology of Greenland halibut and sandeel larvae off West Greenland. Mar Biol 149:937-952

Smayda TJ, Borkman DG, Beaugrand G, Belgrano A (2004) Responses of marine phytoplankton populations to fluctuations in marine climate. In: Stenseth NC, Ottersen G, Hurrell J, Belgrano A (eds) Marine ecosystems and climate variation: the North Atlantic. Oxford University Press, Oxford, p 49-58

Editorial responsibility: Nick Tolimieri, Seattle, Washington, USA
Stige LC, Ottersen G, Brander K, Chan KS, Stenseth NC (2006) Cod and climate: effect of the North Atlantic Oscillation on recruitment in the North Atlantic. Mar Ecol Prog Ser 325:227-241

Taylor AH, Allen IJ, Clark PA (2002) Extraction of a weak climatic signal by an ecosystem. Nature 416:629-632

ter Hofstede R, Hiddink JG, Rijnsdorp AD (2010) Regional warming changes fish species richness in the eastern North Atlantic Ocean. Mar Ecol Prog Ser 414:1-9

$>$ van der Kooij J, Scott BE, Mackinson S (2008) The effects of environmental factors on daytime sandeel distribution and abundance on the Dogger Bank. J Sea Res 60: 201-209

Visbeck M, Chassignet EP, Cyrry R, Delworth T, Dickson B, Krahmann G (2003) The ocean's response to North Atlantic Oscillation variability. Geophys Monogr 134: 113-146

Voigt W, Perner J, Davis AJ, Eggers T and others (2003) Trophic levels are differentially sensitive to climate. Ecology 84:2444-2453

Walther GR, Post E, Convey P, Menzel A, Parmesan C, Beebee TJC, Fromentin JM (2002) Ecological responses to recent climate change. Nature 416:389-395

Wieland K, Jarre-Teichmann A, Horbowa K (2000) Changes in the timing of spawning of Baltic cod: possible causes and implications for recruitment. ICES J Mar Sci 57: $452-464$

Submitted: October 18, 2011; Accepted: March 7, 2012 Proofs received from author(s): May 28, 2012 